\title{
Evidence for Sequential Hermaphroditism in Sabellastarte spectabilis (Polychaeta: Sabellidae) in Hawai $i^{1}$
}

\author{
David R. Bybee, ${ }^{2,4}$ Julie H. Bailey-Brock, ${ }^{2}$ and Clyde S. Tamaru ${ }^{3}$
}

\begin{abstract}
Understanding the reproductive characteristics of Sabellastarte spectabilis (Grube, 1878), an economically important polychaete worm collected for the aquarium trade, is essential to the development of artificial propagation and conservation of coral reefs. The purpose of this study was to determine whether S. spectabilis is hermaphroditic. Using histological techniques, 180 individuals were examined for gametes. Gametes were present only in abdominal segments. Primary oocytes were 7-8 $\mu \mathrm{m}$ in diameter in histologically prepared sections. Sperm appeared as round black dots about $2 \mu \mathrm{m}$ in diameter on histologically prepared slides. Most individuals sampled had only one type of gamete in the coelom, but both eggs and sperm were seen in the coelom of $15 \%$ of individuals, demonstrating the occurrence of hermaphroditism in Hawaiian populations of $S$. spectabilis. The sex ratio of males to females was skewed significantly toward males in both the small $(6-8 \mathrm{~mm}$ diameter) and medium (9-10 $\mathrm{mm}$ diameter) sized worms. Among the largest worms (11-13 $\mathrm{mm}$ diameter), the sex ratio did not diverge significantly from $1: 1$. There was a significantly higher proportion of hermaphrodites $(30 \%)$ in the large size class. Worms of unknown gender, although present in all size classes examined, were most frequent $(33 \%)$ in the medium size class. These patterns are consistent with sequential (protandrous) hermaphroditism.
\end{abstract}

The sabellid polychaete Sabellastarte spectabilis (Grube, 1878) is common in bays and harbors in the main Hawaiian Islands and particularly in Kāne'ohe Bay, on the windward coast of O'ahu. Kāne'ohe Bay is partially cut off from the ocean by a barrier reef, which protects it from large waves and provides an ideal habitat for these softtubed filter feeders. Sabellastarte spectabilis is very abundant in the bay, which is the princi-

1 The PADI Foundation, the Edmondson Fund (University of Hawai'i), and The Center for Tropical and Subtropical Aquaculture provided financial support for this project. This paper is funded in part by grants/ cooperative agreements from the U.S. Department of Agriculture, CSREES Agreement No. 2002-3850012039; National Oceanic and Atmospheric Administration, Project No. A/AS-1, which is sponsored by the University of Hawai'i Sea Grant College Program, SOEST, under Institutional Grant No. NA16RG2254

Pacific Science (2006), vol. 60, no. 4:541-547 (C) 2006 by University of Hawai'i Press

All rights reserved pal collection site for this commercially important ornamental species (Walsh et al. 2003). These worms settle in cracks and crevices of living and dead reef corals, making collection difficult and damaging to the reef community. Reproduction is currently being studied in this species (Bybee et al. in press) with the goal of facilitating artificial propagation to reduce pressure on coral reefs due to destructive collecting practices. 
Polychaetes are predominately gonochoric (separate sexes) (Schroeder and Hermans 1975 ) with hermaphroditism occurring in a minority of families. Of the 9,000 known species belonging to 81 families of polychaetes (Rouse and Pleijel 2001), hermaphroditism has been reported in a total of 67 species among 25 families (Giangrande 1997). About half of the reported hermaphroditic species are sequential hermaphrodites (36); the majority of those (32) are protandrous forms (Giangrande 1997). The remainder (31) are simultaneous hermaphrodites (Schroeder and Hermans 1975, Giangrande 1997).

Gonochorism is also the predominant condition within the Sabellidae, though hermaphroditism is not uncommon. Most of the reported sabellid hermaphrodites are listed as simultaneous, and sequential (protandrous) forms seem to be rare (Rouse and Fitzhugh 1994). However, it has been hypothesized that sequential hermaphroditism is probably more widespread than we know and that more detailed studies are needed to support this supposition (Rouse and Fitzhugh 1994).

There are eight accepted species in the genus Sabellastarte according to the most recent revision (Knight-Jones and Mackie 2003). Of those eight species, only two have any published information on reproductive mode. Runganathan (1943) observed S. magnifica (Shaw, 1800) [later identified as S. indica (Savigny, 1822)] (Rouse and Fitzhugh 1994) to be a simultaneous hermaphrodite. Sabellastarte indica has since been synonymized with S. spectabilis (Knight-Jones and Mackie 2003). Rouse and Fitzhugh (1994) observed three preserved specimens of the same species, two "small" individuals from Kiribati and one from Palau (Belau). All three were reportedly gonochoric. They also examined two preserved specimens of $S$. magnifica. One specimen (from the West Indies) was found to be a simultaneous hermaphrodite and the other (from Puerto Rico) was gonochoric. Understanding the reproductive characteristics of $S$. spectabilis, an economically important worm, is a prelude to the development of means to artificially propagate the species. Determining whether or not this polychaete is hermaphro- ditic and the nature of the hermaphroditism formed the basis for this investigation.

\section{MATERIALS AND METHODS}

Worms were collected at monthly intervals (2002-2003) from the reefs surrounding the Hawai' $i$ Institute of Marine Biology on Moku O Lo'e (also known as Coconut Island) in Kāne'ohe Bay for histological analyses of gametogenesis and examination of their internal anatomy. Whole specimens were fixed in $10 \%$ seawater formalin for a minimum of 72 $\mathrm{hr}$, after which they were transferred to $80 \%$ ethanol for long-term storage. Transverse sections were taken from both the thorax and abdomen of whole worms. Tissue samples were placed in tissue cassettes and were then processed using a tissue processor (Shandon Citadel 2000) and embedded in paraplast with an embedding center (Tissue Tek III). The paraplast blocks were sectioned at a thickness of $4 \mu \mathrm{m}$ using a microtome (American Optical) and placed on microscope slides. The slides with adhered sections were then cleared with xylene and dehydrated through an alcohol series and finally stained with hematoxylin/eosin stain. Individuals were classified as male if only sperm were present and female if only oocytes were found. Those with both male and female gametes were classified as hermaphrodites. Worms with only coelomocytes were classified as unknown. Fresh samples of coelomic contents were also extracted from live worms, and gametes were digitally photographed using a compound light microscope (Nikon Eclipse E200).

The body diameter of worms (removed from tubes) collected during months in which gametogenesis is known to occur (MayNovember) was measured with calipers to the nearest millimeter, and worms were divided into three different size classes (small, 6-8 mm; medium, 9-10 $\mathrm{mm}$; and large, 11$13 \mathrm{~mm}$ ). Worms were further placed into the following reproductive groups: male, female, hermaphrodite, and unknown, based on observations made from the histologically prepared slides. A chi square $\left(X^{2}\right)$ test was used to assess the statistical significance of various levels of abundance between groups. 


\section{Scanning Electron Microscopy}

Scanning electron microscopy (SEM) was used to confirm spermatocytes. This was done by first extracting coelomic contents from several individuals until a male was found. The contents were pipetted from the coelom, then fixed with $4 \%$ gluteraldehyde in 0.1 molar sodium cacodylate buffer (7.6) with 0.35 molar sucrose. They were washed in 0.1 molar sodium cacodylate buffer with 0.44 molar sucrose. Coelomic contents were then postfixed with $1 \%$ osmium tetroxide in buffer and dehydrated in a graded series of ethanol, critical point dried, and mounted on aluminum stubs. They were then sputter coated with gold palladium and viewed in a field emission scanning electron microscope (Hitatchi S-800) at $15 \mathrm{kv}$ accelerating voltage. The abdomen and thorax were also sectioned and prepared for histological processing as just described.

\section{RESULTS}

To date, gender in S. spectabilis cannot be determined visually on whole specimens from external appearance. This makes extraction and wet-mount microscopic examination of coelomic contents or the use of histological preparation and examination of thin sections necessary. Gametes were present only in abdominal sections. Oocytes were first visible on histologically prepared slides at about 7-8 $\mu \mathrm{m}$ in diameter using a compound microscope at $40 \times$ magnification. These cells were composed mostly of a large nucleus containing a dark nucleolus and surrounded by a grainy-textured ooplasm (Figure 1A). Wet mounts of oocytes showed little more than a spherical, gray structure (Figure $1 B$ ) though the nucleus and nucleolus were sometimes visible (Figure $1 C$ ). Sperm cells appeared on histologically prepared slides as round black dots about $2 \mu \mathrm{m}$ in diameter (Figure $1 A$ ). Sperm on wet mounts appeared as small, translucent, circular cells with a faint but long flagellum (Figure 1B,E), which were often very active. A scanning electron micrograph of an individual sperm cell clearly shows the round sperm head and flagellum (Figure
1D). A more detailed description of S. spectabilis larval morphology and discussion of life history implications is found in Bybee et al. (in press). For a review of polychaete spermatozoa morphology see Jamieson and Rouse (1989).

Most worms (85\%) had only one type of gamete in the coelom and were designated as being male or female. Several individuals $(15 \%)$ clearly possessed both oocytes and spermatocytes (Figure $1 A, B$ ) and were classified as hermaphrodites (Table 1). Individuals in which no gametes could be identified were classified as unknown. Observations of coelomic contents of live worms were consistent with histological observations. A histogram (Figure 2) revealed that the sex ratio of males to females was skewed significantly toward males $\left(P<0.01, X^{2}\right.$ test $)$ in both the small and medium size classes. In the large size class, however, the sex ratio did not diverge significantly from $1: 1$. The proportion of hermaphrodites found in the large size class was significantly higher $\left(P<0.05, X^{2}\right.$ test $)$ than what was observed in the small and medium size classes. Worms that were characterized as unknown were most abundant in the medium size class.

\section{DISCUSSION}

From the data presented in the current investigation it appears that many of the smaller worms in the population sampled were males. All four groups (male, female, hermaphrodite, and unknown) were present in all of the size classes examined. It is not clear whether all individuals first become sexually mature as males as is the case with protandrous hermaphrodites. However, within the size range of individuals examined, there is a clear shift in the percentage composition of the sexes, particularly as the worms attain the large size class (11-13 mm diameter). At this size many of the males apparently change gender, becoming females. This is indicated by the significant increase in the proportion of hermaphrodites that is found in the large size class. One clear result of the observed transition in gender is that the sex ratio is more evenly distributed between both sexes. It is 

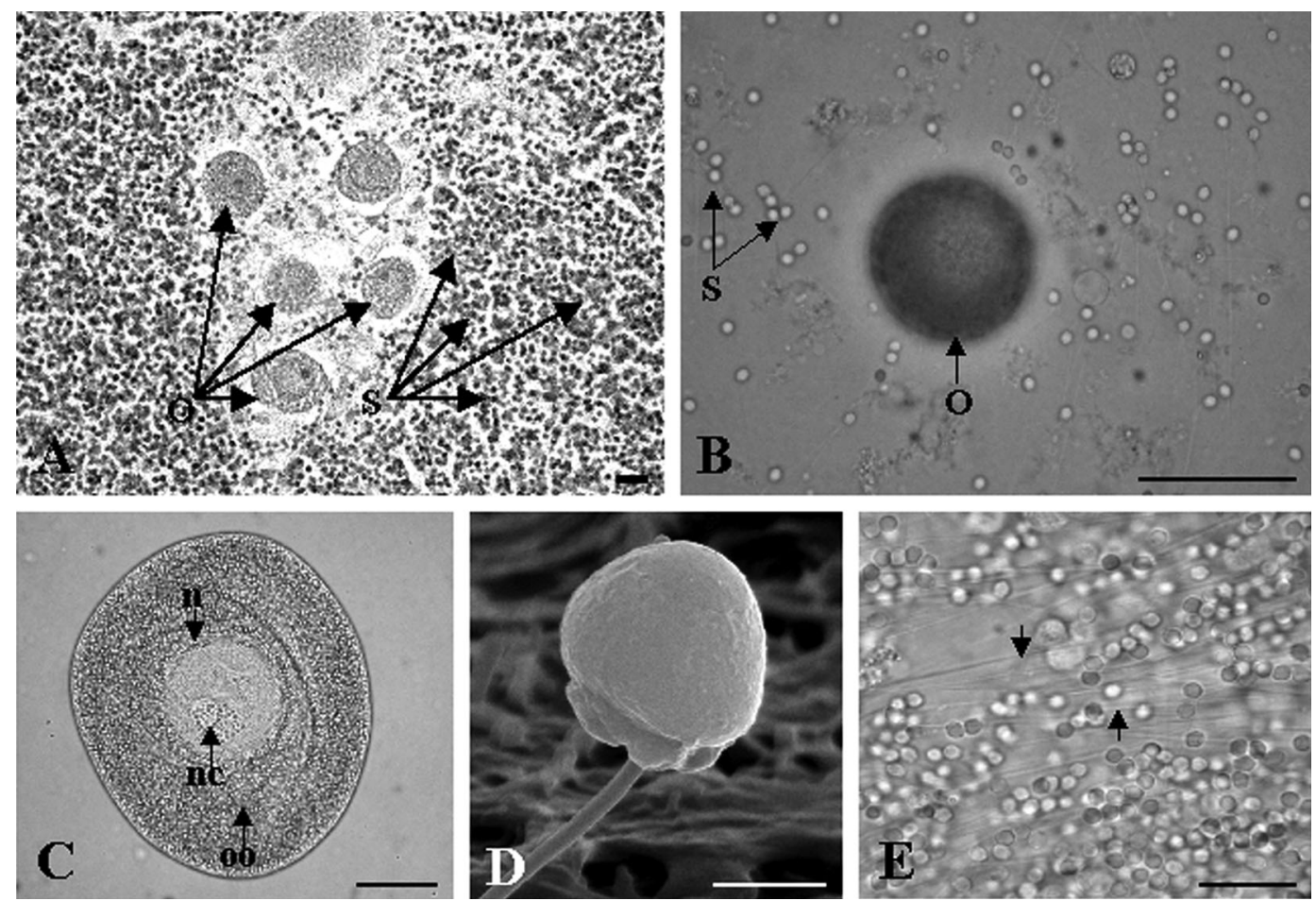

FIgUre 1. Gametes of Sabellastarte spectabilis. A. Both oocytes $(\mathrm{O})$ and sperm $(\mathrm{S})$ in the coelom. Scale bar $=10 \mu \mathrm{m} . B$. Wet mount of coelomic contents showing one egg $(\mathrm{O})$ and several sperm cells (S). Scale bar $=25 \mu \mathrm{m}$. C. An unfertilized egg taken from the coelom showing ooplasm (oo), nucleus (n), and nucleolus (nc). Scale bar $=50 \mu \mathrm{m}$. D. Mature sperm extracted from the coelom showing head and a portion of its flagellum. Scale bar $=10 \mu \mathrm{m}$. E. Sperm cells showing long flagella (arrows). Scale bar $=1.7 \mu \mathrm{m}$.

TABLE 1

Number of Individuals of Sabellastarte spectabilis Collected in Each Size Category

\begin{tabular}{|c|c|c|c|c|}
\hline $\begin{array}{l}\text { Reproductive } \\
\text { Group }\end{array}$ & $\begin{array}{c}\text { Small } \\
(6-8 \\
\mathrm{mm})\end{array}$ & $\begin{array}{c}\text { Medium } \\
(9-10 \\
\mathrm{mm})\end{array}$ & $\begin{array}{c}\text { Large } \\
(11-13 \\
\mathrm{mm})\end{array}$ & Totals \\
\hline Male & 25 & 30 & 16 & 71 \\
\hline Female & 6 & 13 & 19 & 38 \\
\hline Unknown & 11 & 24 & 9 & 44 \\
\hline Hermaphrodites & 3 & 4 & 20 & 27 \\
\hline Totals & 45 & 71 & 64 & 180 \\
\hline
\end{tabular}

not clear whether all of the males will eventually change to females as they continue to grow/age. Likewise, although gametes found in males and females of the smaller size classes appear to be sexually mature, it remains to be determined morphologically whether they are indeed capable of undergoing final maturation, spawning, and production of viable larvae.

Our observation of hermaphroditic individuals in this Hawaiian population of $S$. spectabilis agrees with published observations of the same species in the Indian Ocean (Runganathan 1943 [see introduction]) but differs from observations in the Pacific (appendix 1 in Rouse and Fitzhugh 1994). There are five Sabellastarte species in the Indo-Pacific; some are widespread (Knight-Jones and Mackie 2003). Records and museum identifications before 2003 may well be $S$. spectabilis but need to be confirmed.

There are also differing observations within Caribbean species. Sabellastare magnifica from the West Indies was reported as a 

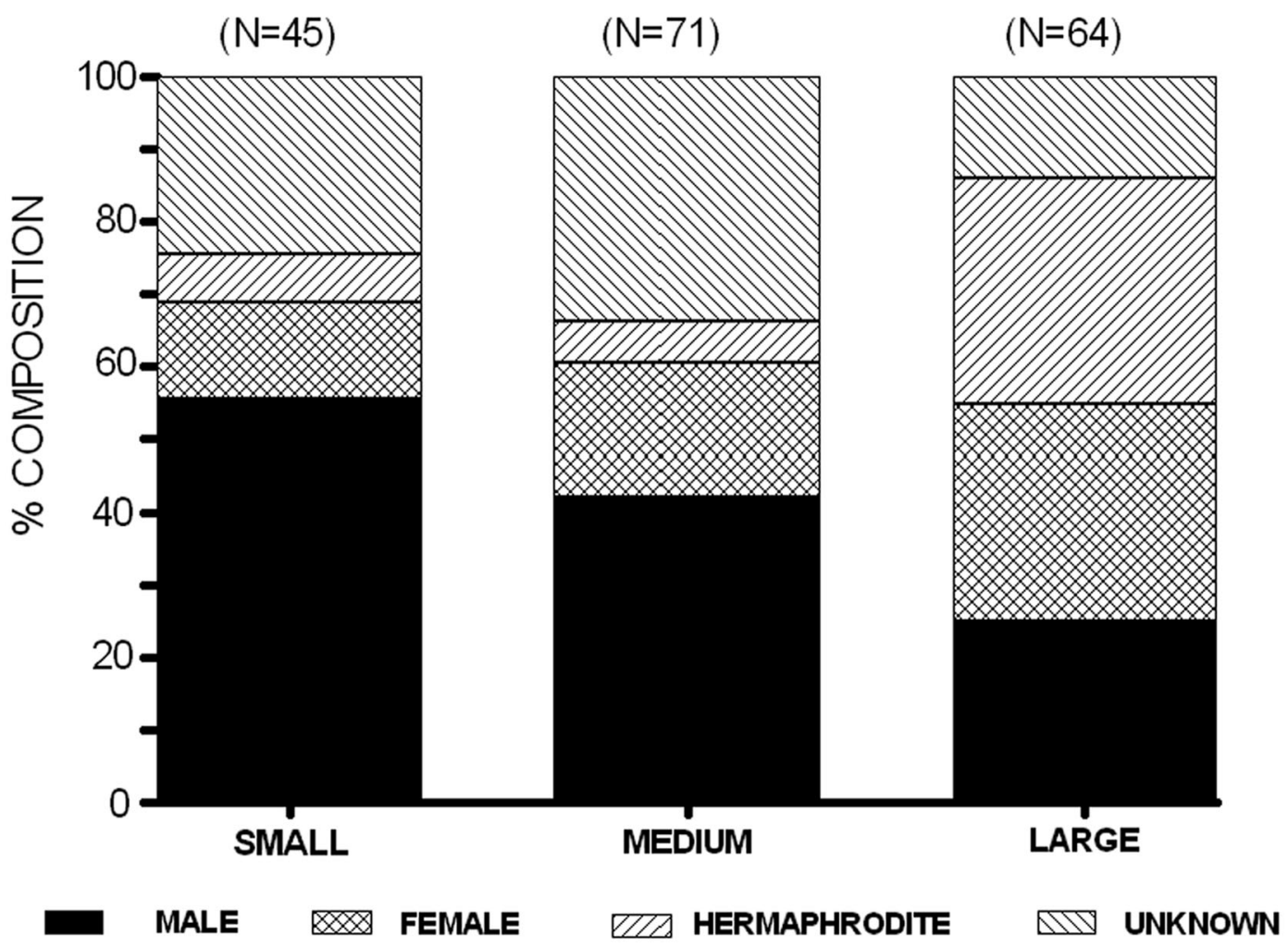

Figure 2. Size classes (from body diameter in $\mathrm{mm}$ ) of Sabellastarte spectabilis collected in this study.

simultaneous hermaphrodite, but the same species from Puerto Rico was determined to be a gonochoric female (Rouse and Fitzhugh 1994). Sabellastarte magnifica is probably the only species of the genus in the Caribbean, yet there seems to be a difference in reproductive mode between the two museum holdings (Rouse and Fitzhugh 1994). It is possible that $S$. magnifica and S. spectabilis display different reproductive modes in different locations (or under different environmental conditions). It is more likely, however, that this tubeworm is a sequential (protandrous) hermaphrodite, which is difficult to detect with so few preserved (museum) specimens. No quantitative size information was available for the reported specimens.

Heath $(1977,1979)$ hypothesized that hermaphroditism is associated with internal fertilization and tube brooding and that gonochorism is found in externally fertilizing broadcast spawners. This does not seem to be the case with S. spectabilis, which is clearly a broadcast spawner with planktonic development of lecithotrophic larvae (Bybee et al. in press).

According to Ghiselin (1974, 1987), hermaphroditism should evolve under three conditions: (1) when finding a mate is difficult, (2) in small, genetically isolated populations, and (3) when one sex benefits from being larger or smaller than the other. With regard to how these conditions may apply to $\mathrm{Ha}$ wai'i's population, finding a mate may be difficult for sessile species like these tubeworms. Because S. spectabilis is believed to be an introduced species to Hawaici (Coles and Eldredge 2002), it is difficult to know what ecological or genetic selective forces may have influenced the evolution of reproductive mode at its location of origin. Females may benefit from being large because eggs 
are larger and require more food resources to produce than sperm. Females with large bodies (more coelomic space) can hold more eggs, thus enhancing their chances of providing larvae with an adequate yolk supply to ensure successful reproduction. The younger, smaller-bodied S. spectabilis may be able to reproduce most effectively by producing sperm. As these worms grow bigger, some may change sex, evening out the sex ratio and enabling the production of a large number of eggs, which is true of many marine organisms (Fleminger 1985, Brook et al. 1994, Rouse and Fitzhugh 1994, Sewell 1994, Giangrande 1997, Svensen and Tande 1999, Cotter et al. 2003, Munoz and Warner 2003).

Results from the current investigation clearly demonstrate that the Hawaiian population of S. spectabilis sampled in this study is hermaphroditic and can be tentatively characterized as being a protandrous hermaphrodite. This is useful information for future phylogenetic and reproductive studies as well as helping to facilitate the culture of this intensely collected marine ornamental species, which we hope will decrease the damage currently done to coral reefs during collection.

\section{ACKNOWLEDGMENTS}

We are most grateful to Ron Shimojo and Lei Yamasaki at 'Ānuenue Fisheries, Honolulu, for assistance with the histology. We are also grateful for the help of I. Carvalho and the Biological Electron Microscope Facility of the University of Hawaii.

\section{Literature Cited}

Brook, H. J., T. A. Rawlins, and R. W. Davies. 1994. Protogynous sex change in the intertidal isopod Gnorimosphaeroma oregonense (Crustacea: Isopoda). Biol. Bull. (Woods Hole) 187:99-111.

Bybee, D. R., J. H. Bailey-Brock, and C. S. Tamaru. In Press. Larval development of Sabellastarte spectabilis (Grube 1878) (Polychaeta: Sabellidae) in Hawaiian waters. Sci. Mar.

Coles, S. L., and L. G. Eldredge. 2002. Nonindigenous species introductions on coral reefs: A need for information. Pac. Sci. 56:191-209.

Cotter, E., R. M. O'Riordan, and A. A. Meyers. 2003. A histological study of reproduction in the serpulids Pomatoceros triqueter and Pomatoceros lamarckii (Annelida: Polychaeta). Mar. Biol. (Berl.) 142:905-914.

Fleminger, A. 1985. Dimorphism and possible sex change in copepods of the family Calanidae. Mar. Biol. (Berl.) 88:273-294.

Ghiselin, M. T. 1974. The economy of nature and the evolution of sex. University of California Press, Berkeley.

- 1987. Evolutionary aspects of marine invertebrate reproduction. Pages 609-655 in A. C. Giese, J. S. Pearse, and V. B. Pearse, eds. Reproduction of marine invertebrates. Vol. IX. General aspects: Seeking unity in diversity. Blackwell Scientific Publications and The Boxwood Press, California.

Giangrande, A. M. 1997. Polychaete reproduction patterns, life cycles, and life histories: An overview. Oceanogr. Mar. Biol. Annu. Rev. 35:323-386.

Heath, D. J. 1977. Simultaneous hermaphroditism: Costs and benefits. J. Theor. Biol. 64:363-373.

- 1979. Brooding and the evolution of hermaphroditism. J. Theor. Biol. 81:151155.

Jamieson, B. G. M., and G. W. Rouse. 1989. The spermatozoa of the Polychaeta (Annelida): An ultrastructural review. Biol. Rev. 64:93-157.

Knight-Jones, P., and A. S. Y. Mackie. 2003. A revision of Sabellastarte (Polychaeta: Sabellidae). J. Nat. Hist. 19:2269-2301.

Munoz, R. C., and R. R. Warner. 2003. A new version of the size-advantage hypothesis for sex change: Incorporating sperm competition and size-fecundity skew. Am. Nat. 161:749-761.

Rouse, G. W., and K. Fitzhugh. 1994. Broadcast fables: Is external fertilization really primitive: Sex, size and larvae in sabellid polychaetes. Zool. Scr. 23:273-301.

Rouse, G. W., and F. Pleijel. 2001. Polychaetes. Oxford University Press, New York. 
Runganathan, V. 1943. On the occurrence of hermaphroditism in Sabellastarte magnifica Shaw together with an account of the excretory organs in the species. Proc. Indian Sci. Congr. 29:150-151.

Schroeder, P. C., and C. O. Hermans. 1975. Annelida: Polychaeta. Pages 1-169 in A. C. Geise and J. S. Pearse, eds. Reproduction of marine invertebrates. Academic Press, New York.

Sewell, M. A. 1994. Small size, brooding and protandry in the apodid sea cucumber Leptosynapta clarki. Biol. Bull. (Woods Hole) 187:112-123.
Svensen, C., and K. Tande. 1999. Sex change and female dimorphism in Calanus finmarchicus. Mar. Ecol. Prog. Ser. 176:93102.

Walsh, W. J., S. P. Cotton, J. Dierking, and I. D. Williams. 2003. The commercial marine aquarium fishery in Hawai'i 19762003. Pages 132-159 in A. M. Friedlander, ed. Status of Hawai'i's coastal fisheries in the new millennium. Proceedings of a symposium sponsored by the American Fisheries Society, Hawai'i chapter. Honolulu. 
